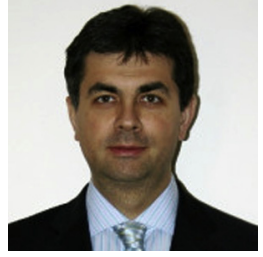

\section{ON BIOSTATISTICIANS AND THEIR ROLE IN CARDIOTHORACIC SURGERY RESEARCH}

\section{To the Editor:}

I enjoyed reading Dr Kurlansky's recent editorial ${ }^{1}$ entitled "Lies, damned lies, and statistics," which focuses on several critical aspects of propensity score matching (PSM). The issue of reduced sample sizes after PSM is a real concern and could be highly consequential when effect sizes are small. When large effect sizes are anticipated, a loss of power may not be as problematic. However, if the common support of the propensity scores in the 2 groups compared is very small, it may be an indication that, on the basis of the covariate data collected, the 2 groups are vastly different in terms of covariate distributions. In this case, even covariate adjustment methods that do not use PSM may not adequately address confounding due to covariate imbalances.

Failure to adjust for unobserved covariates is an adequate criticism of any statistical method used in observational studies, not only of PSM. Regression methods that make use of the entire dataset are equally inadequate for dealing with unobserved potential confounders. One solution is to expand the data-collection process and to quantify and capture additional potential confounders or their surrogates.

The editorial's epigraph, a quotation from Ernest Rutherford, and its content are antithetical. Dr Kurlansky's insights and opinions regarding PSMs and their shortcomings reflect not only his expertise in this area but also the fact that highlevel statistical training is required to adequately understand the statistical underpinnings of the editorial. The fact that the thoracic and cardiac surgery scientific communities have adopted the use of PSM methods with much enthusiasm reiterates the idea that statistical expertise is key in the advancement of the field.

The amazing pace at which medical technology advances will soon generate, some would say that it already does so, vast amounts of new data and with it, new statistical challenges. To be adequately prepared and given the shortage of individuals with high-level quantitative skills, ${ }^{2}$ major professional societies, such as The American Association for Thoracic Surgery, Society of Thoracic Surgeons, Western Thoracic Surgical Association, and others should

\footnotetext{
The Editor welcomes submissions for possible publication in the Letters to the Editor section that consist of commentary on an article published in the Journal or other relevant issues. Authors should: $\bullet$ Include no more than 500 words of text, three authors, and five references. • Type with double-spacing. • See http://jtcs.ctsnetjournals.org/ misc/ifora.shtml for detailed submission instructions. • Submit the letter electronically via jtcvs.editorialmanager.com. Letters commenting on an article published in the JTCVS will be considered if they are received within 6 weeks of the time the article was published. Authors of the article being commented on will be given an opportunity of offer a timely response ( 2 weeks) to the letter. Authors of letters will be notified that the letter has been received. Unpublished letters cannot be returned.
}

perhaps enhance and increase their efforts to attract highlevel statistical talent to this exciting field. A good starting point could be the inclusion of continued education modules, in the form of short courses and tutorials, during their annual meetings. Modern data analysis methodologies have seen an explosive development in the recent years, and their incorporation into the mainstream practice could play a critical role in advancing the field. The development of methodological grant initiatives focused on biostatistical methodology and immediate cardiovascular and cardiothoracic applications could represent another potential pathway toward this goal.

Adin-Cristian Andrei, PhD
Northwestern University
Feinberg School of Medicine

Chicago, Ill

\section{References}

1. Kurlansky P. Lies, damned lies, and statistics. J Thorac Cardiovasc Surg. 2015; 150:20-1.

2. Lohr S. For today's graduate, just one word: Statistics. The New York Times. August 5, 2009;158.54759 A1.

http://dx.doi.org/10.1016/j.jtcvs.2015.06.073

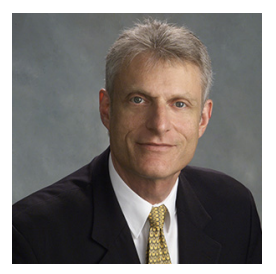

BIOSTATISTICIANS AND THE FUTURE OF CARDIOVASCULAR RESEARCH

Reply to the Editor:

I thank Dr Andrei for his kind comments and welcome the enthusiasm and insight reflected in his suggestions. Just as propensity score matching has been introduced as an analytic tool to assist in harvesting the useful information that can be gleaned from retrospective clinical registries, newer techniques will be essential to meet the challenges of meaningful future research. The explosive acceleration in computer processing capabilities has opened the door to both access and integration of huge data sets - administrative, clinical, genomic, metabolic, and so on. Clearly the researcher of the future will benefit not only from a strong foundation in statistical methodology but also from the active collaboration with experienced statistical analysts. In this context, the attention and professional support advocated by Dr Andrei will only help to facilitate this process-and advance our future research.

Paul Kurlansky, MD

Department of Surgery

Columbia University

New York, NY

http://dx.doi.org/10.1016/j.jtcvs.2015.07.065 